\title{
Anti-hypertensive effect of Korean fermented soybean paste (Doenjang) through regulation of the renin-angiotensin system (RAS) in male rats fed with high-fat and/or high-salt diet
}

Hayoung Woo

Jeonbuk National University

Jung Eun Park

Jeonbuk National University

Youn-Soo Cha ( $\square$ cha8@jbnu.ac.kr)

Jeonbuk National University https://orcid.org/0000-0001-5579-650X

\section{Research}

Keywords: Doenjang, High fat diet, Renin-angiotensin system, Hypertension

Posted Date: April 12th, 2021

DOI: https://doi.org/10.21203/rs.3.rs-320019/v1

License: (a) (i) This work is licensed under a Creative Commons Attribution 4.0 International License. Read Full License 


\section{Abstract}

Background: Korean fermented food, doenjang, is questioned due to its high salt content, although it has been reported an abundance of beneficial effects. Therefore, we investigated its impact on reninangiotensin system (RAS) hypertension using 3T3-L1 adipocytes and male Sprague-Dawley rats.

Results: Among the rats fed with normal diet (ND), high-fat diet (HD), high-fat diet with $8 \%$ table salt (HDS), or high-fat diet with doenjang containing $8 \%$ table salt (HDJ) for 13 weeks, the HDJ group showed significantly lower blood pressure, lesser body weight, and reduced levels of serum angiotensin II and aldosterone, compared to the HD and HDS groups. In addition, mRNA expressions levels of angiotensinogen, angiotensin converting enzyme, angiotensin II receptor type 1, and angiotensin II receptor type 2 were downregulated in epididymal fat of the HDJ group.

Conclusions: In spite of its high salt content, Doenjang appears to inhibit obesity-induced hypertension through modulation of RAS by blocking the angiotensin converting enzyme, even with high fat intake.

\section{Background}

The incidence of obesity is increasing due to the imbalance between energy intake and consumption, and hence obesity is becoming a global health burden [1]. The prevalence of obesity and obesity-related diseases is increasing worldwide [2]. It is one of the major risk factors for hypertension [3]. Weight gain is related to increased blood pressure; about $60-70 \%$ of hypertensive adults excess adiposity [2]. According to WHO, hypertension is estimated to afflict 1.13 billion people worldwide. In 2015, one in five women and one in four men were predisposed to hypertension [4]. Indeed, it is more difficult to regulate blood pressure in obese patients than in ordinary people, and obesity is recognized as a common cause of treatmentresistant hypertension [5].

The Renin-angiotensin system (RAS) is well known for involved in controlling blood pressure and fluid/electrolyte balance. Activated RAS is a common aspect of metabolic syndrome patients [6]. Angiotensinogen $(A g t)$ is the precursor of the bioactive angiotensin peptides, angiotensin I (Ang $I$ ) and angiotensin II (Ang I), produced through two enzyme cleavages, which are renin and angiotensinconverting enzymes (Ace), respectively [7]. RAS regulates blood vessel constriction, and reabsorption of $\mathrm{Na}^{+}$and water [8]. Recent studies have reported that RAS affects obesity and insulin resistance. Adipose tissue is described as an endocrine organ, which plays a significant role in energy metabolism, and contains all RAS components [9].

Korean traditional soybean paste, called doenjang, is known to have antiobesity effects [10]. Doenjang is one of the representative products of South Korea. It is prepared using brine and fermented Meju and mixed with salt (Fig. 1). The enzyme secreted by Bacillus breaks down the soybean protein and produces an amino acid that creates a savory taste [11]. Doenjang is rich in flavonoids, vitamins, minerals, and phytoestrogens, which are the constituents of soybean. Soybeans also contain isoflavones, which have antioxidant, anticancer, anti-inflammatory effects, and can prevent coronary heart diseases [12,13]. Several 
in vitro and in vivo studies have shown the health benefits of doenjang and its active compounds. Our previous clinical studies have reported its antiobesity, antioxidant effects, and its beneficial effects on overall health index. However, consumption of doenjang is still questioned, because of its high salt content [12]. Salt is added during the manufacturing of doenjang to control the harmful microbial growth and improve its preservation. It promotes the growth of beneficial microbe, inhibits undesirable fermentation, and improves its taste. [11]. However, excessive sodium intake is generally known to increase the risk of hypertension through hypervolemia, promote heart and kidney disease, and contribute to stroke and gastric cancer $[14,15]$.

In our previous study, we had investigated how doenjang regulates hypertension caused by a high-salt diet. Doenjang, when fed along with normal diet, caused a significant reduction in the blood pressure and lowered the expression of sodium transferase-related genes, as compared to the same amount of salt alone. [16,17].

In the present study, the antiobesity and antihypertensive effects of traditional fermented foods in the obese condition were studied in various ways. Here, we considered the salt content, which is different from the previous research, which focused on the effects of doenjang effects in normal conditions. We included high-fat as well as high-salt diets in our experiments, which have investigated few other studies, and the results were inconclusive yet [18]. High-salt and high-fat diets synergistically promote obesity and high blood pressure [3]. Purpose of this study was to examine the effect of a combination of high-salt and highfat diet on RAS in adipocytes and how doenjang containing high amount of salt, regulates obesity and blood pressure, even when consumed together with a high-fat diet.

\section{Materials And Methods}

\section{Preparation of Doenjang}

Doenjang was produced by the Sunchang Sauce Corporation of South Korea (Sunchang-gun, Jeollabuk-do, Korea). This fermented food is prepared using soybean after maturing it for 6 months, by traditional Korean fermentation process (Fig. 1). After steamed soybeans, it was made into blocks, and fermented with Aspergillus oryzae and Bacillus subtilis for one month. After this, it was mixed with brine (saltwater, $26 \%, w / v)$ in a 1:3 ratio and further fermented for 2 more months. Once matured, doenjang was dried using a freeze-dryer (FD12008, Ilshin Biobase, Gyeonggi-do, Korea), and its salinity was adjusted with $\mathrm{NaCl}$ (Samchun, Pyeongtaek-si, Gyeonggi-do, Korea) to 8\%, using Mohr's method.

\section{Animals and treatments}

Three-week-old male Sprague-Dawley rats were purchased from Central Lab. Animal, Inc. (Seoul, Korea), and acclimated at $12 \mathrm{~h}$ light and $12 \mathrm{~h}$ dark cycles at $25 \pm 2^{\circ} \mathrm{C}$ and humidity $50 \% \pm 5 \%$ conditions. After 7 days adaptation, they were randomly (no diffrence in body weight and initial SBP) divided into 4 groups $(n=6)$; normal diet control (ND; AIN76A, Research Diets, Inc. New Brunswick, NJ, USA), high-fat diet control (HD; 60\% fat by weight, D12492, Research Diets, New Brunswick, NJ, USA), high-fat diet with $8 \%$ table salt (HDS), and a high-fat diet with doenjang containing $8 \%$ table salt (HDJ). All animals were fed with their 
corresponding experimental diets (Table 1) for 13 weeks, with water supplied. Body weights were noted once a week and food intake was measured each day. Systolic blood pressure (SBP) was recorded weekly by the indirect tail-cuff method (BP-2000, Visitech Systems, Inc., Apex, NC, USA) 30 min after placing them at $37^{\circ} \mathrm{C}$. The mean SBP was recorded after 7 measurements. During the last 4 weeks, the animals were individually housed in metabolic cages $24 \mathrm{~h}$ for 3 consecutive days in a week, with water provided through drinking bottles and food in the cage. Food and water intake, and fecal and urine output were measured and collected for analyses. Mean value of each criterion was recorded for each rat. All animal procedures were approved by the Animal and Use Committee of Chonbuk National University (CBNU 2018-052).

\section{Tissue collection}

At the end of 13 weeks, rats were fasted for $12 \mathrm{~h}$ before anesthetizing with $2 \mathrm{mg} / \mathrm{kg}$ BW alfaxan (Jurox, Australia) and $0.5 \mathrm{~mL} / \mathrm{kg} \mathrm{BW}$ rompun (Bayer, Seoul, Korea) through intramuscular injection to collect blood and tissues. Liver, epididymal adipose tissue, and one of the kidneys were rinsed with saline, weighed, and immediately frozen in liquid nitrogen and stored at $-80^{\circ} \mathrm{C}$ for further analyses. The other kidney was fixed in $10 \%$ formaldehyde and embedded in paraffin. Blood was drawn by orbital vein puncture and centrifuged at $3,000 \mathrm{rpm}$ for $15 \mathrm{~min}$ at $4^{\circ} \mathrm{C}$ to collect serum.

\section{Biochemical analysis}

The serum levels of renin, angiotensin II and aldosterone were measured using assay kits (Rat Renin ELISA Kit, MyBioSource, San Diego, CA, USA; Angiotensin II ELISA Kit, and Aldosterone ELISA Kit, Enzo Life Sciences, Inc., Farmingdale, NY, USA), following the manufacturer's protocols.

\section{Histology of fat cryosections}

Frozen epididymal adipose tissues were cryopreserved in OCT (Scigen Scientific Gardena, CA, USA), and frozen in liquid nitrogen. Sections of $10 \mu \mathrm{m}$ thickness were cut with cryomicrotome (Shandon Cryotome FE, Thermo Scientific, MA, USA), transferred onto glass slide (Marienfeld, Germany) at $-30^{\circ} \mathrm{C}$. Sections were stained with hematoxylin and eosin (H\&E) and mounted in glycerol gelatin. Cells were observed using an Axiophot Zeiss Z1 microscope (Carl Zeiss, Gottingen, Germany) at X200 magnification, and adipocytes were counted. Difference in cell size in each group were noted.

\section{RNA extraction and real-time PCR}

Total RNA was isolated from after homogenizing the tissues in TRIzol reagent (Invitrogen, Grand Island, NY, USA), and the concentration of total RNA was equalized using quantifying on Biodrop Duo (Biochrom, Holliston, MA, USA). cDNA was synthesized using PrimeScript ${ }^{\mathrm{T}}$ RT Master Mix (Takara Bio Inc., Shiga, Japan) according to the manufacturer's instructions. RNA expression was measured by quantitative realtime polymerase chain reaction (qPCR) using the SYBR Green real-time PCR master mix (TOYOBO, Osaka, Japan), on a 7500 Real-Time PCR system (Applied Biosystems, Foster City, CA, USA), and quantitative analysis of PCR data were calculated through $2^{-\Delta \Delta C t}$ method, using beta-actin as an internal control. Primers used for the qPCR are listed in Table 2. 


\section{Urine and feces analyses}

Urine and feces samples, collected from metabolic cages, were analyzed for their $\mathrm{Na}^{+}$and $\mathrm{K}^{+}$contents, by inductively coupled plasma-mass spectroscopy (ICP-MS; 7500A, Agilent Technologies, Germantown, MD, USA), the center for University-Wide Research Facilities (CURF) at Jeonbuk National University.

\section{Analyses of serum ion levels}

The $\mathrm{Na}^{+}$and $\mathrm{K}^{+}$concentrations in the serum were determined using Fuji Dri-Chem Slide Na-K-Cl (FUJIFILM, Tokyo, Japan) with FDC 3500i chemistry analyzer (Fuji Dri-Chem Analyzer, Tokyo, Japan).

\section{Preparation of doenjang samples for treating the cell line}

Doenjang was purchased from the Sunchang Sauce Corporation of South Korea (Sunchang-gun, Jeollabuk-do, Korea). The $1 \mathrm{gram}$ of each freeze-dried doenjang was mixed with $10 \mathrm{~mL}$ of solvent (80\% ethanol) at RT for $24 \mathrm{~h}$ on a shaker. The supernatants were collected and filtered through ADVANTEC No. 2 filter paper, and $1 \mathrm{~mL}$ of each filtrate was freeze-dried in a speed vacuum concentrator (FD12008, Ilshin Biobase, Gyeonggi-do, Korea).

\section{Study design and cell culture}

The 3T3-L1 preadipocyte cell line ((CL-173)-ATCC, VA, USA) was maintained in DMEM (Hyclone, USA) containing $10 \%$ bovine serum (Gibco, NY, USA) and $100 \mathrm{U} / \mathrm{mL} 1 \%$ penicillin-streptomycin (Hyclone, USA) at $37^{\circ} \mathrm{C}$ under $5 \% \mathrm{CO}_{2}$ in a humidified incubator. RNA was extracted from 3T3-L1 cells at different times after differentiation. In order to observe the effect of RAS blockers, the 3T3-L1 cells were seeded in 6-well plates and upon reaching $100 \%$ confluence (day 0 ), they were continued in culture for $48 \mathrm{~h}$. Then the growth medium was replaced with differentiation medium, containing DMEM, $10 \%$ fetal bovine serum (FBS), 0.5 $\mu \mathrm{M}$ isobutylmethylxanthine (IBMX), $1 \mu \mathrm{M}$ dexamethasone (DEXA), and $10 \mu \mathrm{g} / \mathrm{mL}$ insulin (Sigma-Aldrich Co., St. Louis, MO, USA) with or without Losartan $\left(10^{-4} \mathrm{M}\right)$, Captopril $\left(10^{-4} \mathrm{M}\right)$, or doenjang $(0.4 \%$ salinity). All treatments chemicals were dissolved in $30 \% \mathrm{EtOH}$ to match the stock concentrations (Fig. 7). The media, with or without the treatment chemicals, were changed every day, and the cells were harvested on the day 4. Total RNA was extracted using TRIzol reagent, according to the manufacturer's instructions (Invitrogen) and quantified by quantitative real-time PCR with gene-specific primers (Table 3).

\section{Statistical analyses}

Results are expressed as mean \pm standard error of means (SEM). Statistical analysis was performed using SPSS 17.0 (SPSS, Inc., Chicago, IL, USA). One-way ANOVA and Duncan's multiple range test were used for comparison involving three or more groups, and $p<0.05$ was considered statistically significant.

\section{Results}

\section{Body weight, diet intake, and blood glucose level}


The initial body weight of the animals did not vary significantly among different groups. After 13 weeks on treatment diets, mean body weight of the HD group rats had significantly increased, as compared to those from HDS and HDJ groups, while the ND group had the lowest body weight (Fig. 2). The group treated with doenjang with high-salt, displayed a protective effect against high-fat induced obesity. Diet intake among different groups fed normal diet (ND), and high-fat diet (HD, HDS, HDJ) was not significantly different, respectively (Table 3). Compared to the ND group, the blood glucose levels were elevated in the HD and HDS groups, whereas doenjang supplementation markedly attenuated this high-fat diet induced increase in blood glucose (Table 3).

\section{Adipocyte morphology}

Animals from the HD and HDS groups showed a significantly higher weight of epididymal fat, compared to HDJ and ND groups (Fig. 3a). However, doenjang treated rats from the high-fat diet group showed significantly reduced epididymal fat mass, as well as reduced size of adipocytes in it (Fig. 3b). The ratio of the number of adipocytes to area, was significantly increased in the HDJ group as shown in the histological analysis (Fig. 3c).

\section{Expression of obesity related genes}

In order to study the effects of doenjang on obesity, the expression of genes related to lipid-regulating enzymes and transcription factors were quantified in the epididymal adipose tissue. Doenjang treated rats showed significantly lower expression of leptin mRNA in the epididymal adipose tissue. In contrast, adiponectin expression was upregulated due to doenjang supplementation (Fig. 4).

\section{Systolic blood pressure}

The base-line SBP in all groups was $110 \pm 10 \mathrm{~mm} \mathrm{Hg}$, which was significantly increased with high-salt intake over the experimental period, in spite of weight loss. However, SBP of the HDJ group was comparable to that of ND, even though the HDJ diet had the same amount of salt as HDS, indicating that the high-salt content in doenjang did not alter the SBP, unlike HDS. Animals from HDJ and ND groups had steady and normal SBP compared to those from HD group also, HDS group showed significantly higher SBP in the last week of the treatment, and it appeared to have reached a plateau at a high of $169.31 \mathrm{~mm}$ $\mathrm{Hg}$ (Fig. 5).

\section{Renin, angiotensin II, and aldosterone levels in serum}

Serum renin level was the highest in the ND group, while the high-fat diet groups showed slightly lower level compared to ND group, still the difference was not significant, whereas only HDS group had significantly less serum rennin than ND group (Fig. 6). Although serum angiotensin II did not significantly decrease in the HDS group compared to the HDJ group, it showed at reducing trend in the latter (Fig. 6). Serum aldosterone also decreased significantly in HDJ (Fig. 6).

\section{Expression of RAS-related genes in adipose tissue}


Expression levels of RAS related genes in adipose tissue, angiotensinogen (Agt), renin, and angiotensinconverting enzyme (Ace) mRNA were notably downregulated in HDJ group, whereas they were comparable in HD and HDS groups (Fig. 23-25). Furthermore, animals from the doenjang group showed reduced expression of lipogenic genes, including angiotensin II receptor type 1 (Agtr1) and angiotensin II receptor type 2 (Agtr2), as compared to those from the high salt group (Fig. 7).

\section{Expression of RAS-related genes in kidney and liver}

Doenjang treatment reduced Agt expression in the liver (Fig. 8), and Agtr1 in the kidney (Fig. 8), which indicated vasodilation of blood vessels, whereas Ace and Agtr2 in the kidney did not change significantly (Fig. 8). mRNA expression of kidney renin, a feedback controller of angiotensinogen, was upregulated in the doenjang-fed group compared to the high-fat, and high-salt groups (Fig. 8). Aldosterone-related genes in kidney, including Star, Hsd3b1, Cyp11a1, Cyp21, and MR, were downregulated by doenjang. In particular, transcription of Cyp21 and MR was drastically reduced in the doenjang group (Fig. 9a). Level of renalase deficiency of which increases the blood pressure, was suppressed in both HD and HDS groups, while in HDJ group, it was enhanced (Fig. 9b).

\section{Serum $\mathrm{Na}^{+} / \mathrm{K}^{+}$levels and their excretion}

After $24 \mathrm{~h}$ in metabolic cages, animals from the HDS and HDJ groups showed a greater amount of water intake and urine excretion than those from the ND and HD groups (Fig. 10). Concentrations of sodium and potassium in both urine and feces were significantly higher in the HDJ group than in the HDS group. However, the ratio of $\mathrm{Na}^{+} / \mathrm{K}^{+}$was the highest in the latter.

Serum analysis showed that HD group had the highest concentration of sodium in their serum. In the HDJ group serum sodium levels showed decreasing tendency among the high-fat diet groups, while the serum potassium level decreased significantly in the HDJ group unlike in the HDS group (Table 4).

\section{Effects of Doenjang extract on 3T3-L1 cell line}

As shown in Fig. 11, treatment with only doenjang could lower the key adipogenic transcription factor, Pparg, significantly in the differentiated adipocyte after 4 days of exposure, and this was similar to the effects of losartan and captopril. Expression of Agt also reduced due to doenjang and captopril over the levels seen in the control. Similarly Ace gene expression decreased significantly due to treatment with doenjang as in the positive control group, treated with Captopril, an Ace inhibitor (Fig. 11).

\section{Discussion}

Both high-salt and high-fat diets are closely linked and synergistically promote obesity and hypertension. Consumption of high-fat is associated with abnormal accumulation of fat, resulting in an increase in the adipocyte size and/or number [19]. High intake of salt induces hypertension, and extracellular fluid accumulation when the osmolality increases in the extracellular space, due to high $\mathrm{Na}^{+}$concentration [20]. Previous studies have shown that doenjang inhibits lipid accumulation in the adipocytes. High sodium 
content also has been reported to suppress the weight gain with the intake of high-fat diet [21]. Present study showed that doenjang and high-salt, lowered the body weight to a level comparable to that of the normal diet fed animals (Fig. 2). Salt affects the activity of renin and angiotensin, and controlled digestive efficiency, and reduces the ability of the gastrointestinal tract to extract calories from the food [21]. This appears to be the underlying mechanism of the body weight reduction in the HDS group. However, bodyweight and obesity-related biomarkers in the HDS group showed an inverse relationship. Adipocyte hypertrophy and hyperplasia were observed in the HD and HDS groups. Interestingly, in the HDJ group had significantly decreased adipocyte size, epididymal fat weight; simultaneously it significantly increased the number of adipocytes to area ratio compared to the HD and HDS group (Fig. 3).

Doenjang, which has soybean as its main ingredient, contains different soy proteins, soy saponin, phospholipids, and isoflavones. These components in soybeans are responsible for its hypolipidemic and antiobesity effects, through increasing $\beta$-oxidation and inhibiting fatty acid synthesis $[10,22]$. Our previous study showed that doenjang has been lowered bodyweight and improved obesity-related parameters such as insulin, leptin, Pparg, and Acc [15]. The results of the present study also confirmed the antiobesity effect of doenjang evident by the decreased gene expression of leptin, while increased adiponectin levels (Fig. 4). Chronic intake of high-salt diet may increase the risk of renal injury, kidney dysfunction, and hypertension in normal rats [23]. Interestingly, in this study, blood pressure was significantly different in the HDS and HDJ groups, in spite of similar body weights and the same amount of salt intake (Fig. 5). The biopeptides present in doenjang may be responsible for its action on RAS, reducing the blood pressure in HDJ group [24].

Obesity is known to induce greater sensitivity towards the changes in blood pressure. Our previous study had indicated that the Korean traditional fermented soybean foods, doenjang and ganjang, reduce the blood pressure in normal SD rats $[16,17]$. RAS is a critical homeostatic regulator that relies on a feedback regulation to achieve and sustain the delicate balance in the blood pressure, required for healthy physiological function [25]. It is activated in the adipose tissue in diet-induced obesity. Expression of systemic RAS is also upregulated in obesity [26]. Therefore, we fed the rats with a high-fat diet to induce obesity and treated them with doenjang to study the effects of doenjang on RAS expression in adipocytes. Our results showed that expression of adipocyte RAS related genes was significantly downregulated by doenjang compared to the salt group. Expression of $A g t$, the first component of the adipocyte RAS, is positively correlated with adipose mass. Renin, Ace, and Agtr1 genes are also upregulated in adipose tissue in obesity [27,28]. Ang II promotes lipogenesis by activating Agtr2, and simultaneously, by decreasing lipolysis by activating Agtr1 [29]. The results of the current study also confirmed that doenjang reduced lipid accumulation through Agtr1 and Agtr2, leading to suppression of obesity. Adipose-derived angiotensin is also released into the systemic circulation, which regulates the activation of bioactive Ang II, leading to increased levels of plasma Ang II, ultimately resulting in elevated blood pressure. Adipocyte RAS contributes to control of fat mass and can affect systemic functions such as metabolism [27,30]. Increased excretion of Agt from fat tissue into the plasma may elevate plasma $\mathrm{Agt}$, resulting in increased blood pressure in the obese [6,30]. Our results indicated that adipocyte Agt had a pattern similar to that of 
plasma angiotensin, which was derived from the liver, and we found that the hepatic Agt was also elevated (Fig. 7).

In this study, we evaluated serum levels of RAS and its mRNA expression in kidney. Serum level of renin in the ND group was higher than that in the HDS and HDJ groups, despite the low blood pressure. This is because, in response to the low sodium level in blood, renin is activated [32]. Lower renin levels may be due to abnormal reabsorption of excess renal sodium, decreased renin secretion, and genetic abnormalities in RAS or related genes. High renin hypertension, as well as low renin hypertension appear to be linked with end-stage organ damage, and worsen the prognosis of hypertension than the hypertension with normal renin levels [33]. High concentration of renin is not always associated with high enzyme activity, but it is directly proportional to renin mRNA expression, renin secretion, and plasma renin activity [16,34]. A previous study has also shown that renin mRNA expression tended to be suppressed by the high-salt diet [35]. It appears that renal renin may affect serum renin. Non-proteolytically enhanced catalyzing activity of renin or pro-renin, when bound to pro-renin receptor (PRR), elevates angiotensin I production from angiotensinogen, thereby enhancing RAS [36]. Reduced renin can be explained through a negative feedback loop involving Ang II, which regulates expression and secretion of renin [37]. The present study showed that serum Ang II and renal Ace were higher in the high-salt group as a result of upregulated Ang II, leading to the downregulation of renin through the negative feedback loop. The patterns of Ace gene expression are similar to systemic Ace activity [8]. Systemic Ace is the main enzyme responsible for the production of Ang II from Ang I in the intravascular space [38]. Ang II enhances hypertension by increasing oxidative stress and activating angiotensin II receptors [39]. In this study, the levels of Agtr1 in the kidney showed a decreasing trend in the HDJ group, while Agtr2 increased significantly in the doenjang group, compared to the high-salt group (Fig. 8). Agtr1 is distributed throughout the kidney and contributes to most of the Ang II actions [40]. Ang II activates Agtr1 to bring about a variety of biological responses, such as vasoconstriction, renal sodium reabsorption, cell proliferation, cell dedifferentiation, and growth, and increased aldosterone secretion, which contribute to increased blood pressure and the development of hypertension [41]. Actions mediated through Agtr2 generally counterbalance the actions of Agtr1 [40]. Aldosterone levels in serum, catalyzed by Ang II, were significantly decreased in the ND and HDJ groups, compared to the levels in HD and HDS groups in the present study (Fig. 6). Similar trends were also observed in aldosterone-related mRNA expression in the kidney. Expression of Star, Hsd3b1, Cyp11a1, Cyp21, and MR genes decreased in the HDJ group (Fig. 9a). In particular, doenjang reduced the expression of Cyp21 and MR genes significantly. Aldosterone is synthesized by the action of Cyp21 in the adrenal cortex [42]. Mineralocorticoid receptor (MR), a ligand-dependent transcription factor, mediates the actions of aldosterone in different tissues [43]. Ang II causes vasoconstriction and activates aldosterone, a mineralocorticoid that reabsorbs sodium in the distal tubules and collecting ducts of the kidney at the expense of potassium excretion. This increased vasoconstriction and sodium reabsorption contribute to higher blood pressure and fluid retention [44]. In accordance with this mechanism, our study showed that serum $\mathrm{Na}^{+}$levels were only marginally higher in the HDS group than in the HDJ group, but no significant difference was observed, whereas serum $\mathrm{K}^{+}$levels were significantly higher in the HD and HDS groups (Table 4). Release of aldosterone from the adrenal cortex is enhanced by high serum concentration of potassium, regardless of the action of Ang II [40]. Consumption of high-salt diets increases the frequency 
of urination, because of the stimulated thirst, and excessive water intake [45]. Our study also demonstrated that water intake and urine output increased significantly in the high-salt and doenjang groups due to $8 \%$ of salt was contained in the HDS and HDJ diets (Fig. 10).

Potassium excretion in urine and feces was significantly lower in the HDS group than in the HDJ group in the present study, while sodium excretion was not noticeably different. Moreover, the $\mathrm{Na}^{+} / \mathrm{K}^{+}$ratio was the highest in the HDS group (Table 4). This ratio in urine may contribute to the deterioration of renal function. It was found that the higher the sodium excretion through urine, the lower the potassium excretion, which means that the elevated urine $\mathrm{Na}^{+} / \mathrm{K}^{+}$ratio is associated with increased blood pressure, leading to faster deterioration of renal function [46]. Kidney RAS is essential for $\mathrm{Na}^{+}$excretion, and for controlling blood pressure [41]. It can also act independent of plasma RAS level upon high-salt intake. Aberrant activation of the kidney RAS generates several factors responsible for hypertension, regulated by a variety of pathophysiological mechanisms related to hypertension and kidney damage [17,39]. The kidney RAS was found and identified to be possibly related to modulation of renalase enzyme. Increased dietary sodium intake decreases the renalase levels in kidney and plasma, and significantly increases the expression of Agtr1 in kidney, a critical element of kidney RAS [47]. Similarly, in the present study, high-salt intake induced kidney RAS, and it reduced the expression of renalase gene in the renal tissue (Fig. 9b).

Exact mechanism of action and the target of doenjang were determined using 3T3-L1 cell line, and compared them with those of Losartan and Captopril, which are antihypertensive drugs that inhibit Agtr1 and Ace, respectively, in the adipocytes. Pparg, Agt, and Ace reduced significantly in the 3T3-L1 adipocytes treated with doenjang (Fig. 11), indicating that fat production was inhibited by doenjang. Therefore, all these data revealed that doenjang regulates blood pressure through RAS, by inhibiting Ace in adipocytes.

\section{Conclusion}

Results of this study revealed that doenjang exerts its beneficial effects by reducing body weight, white adipose tissue, and lipid contents of serum and liver, and improves the obesity-induced high blood pressure. Doenjang supplementation downregulated the expression of genes related to adipocyte RAS, leading to the regulation of systemic RAS. This, in turn, affects the kidney RAS, which ameliorates kidney dysfunction and metabolic syndrome. In the doenjang treated rats, serum ions and excretion of $\mathrm{Na}^{+}$and $\mathrm{K}^{+}$ ions differ drastically from those treated with high salt. To sum up, it is clear that doenjang ameliorates hypertension by suppressing the elevated blood pressure, even though it contains high-salt. Our data suggests that doenjang may inhibit Ace in adipocytes, through a mechanism similar to that of Captopril.

\section{Abbreviations}

Ace: Angiotensin-converting enzymes

Agt: Angiotensinogen

Agtr1: Angiotensin II receptor type 1 
Agtr2: Angiotensin II receptor type 2

Ang I: Angiotensin I

Ang II: Angiotensin II

Cyp11a1: cholesterol side-chain cleavage enzyme

Cyp21: 21-hydroxylase genes

Hsd3b1: 3ß-hydroxysteroid dehydrogenase type 1

MR: Mineralocorticoid receptor

Ppary: Peroxisome proliferator-activated receptor gamma

RAS: Renin-angiotensin system

SBP: Systolic blood pressure

Star: Steroidogenic acute regulatory protein

\section{Declarations}

Ethics approval and consent to participate: All animal procedures were approved by the Animal and Use Committee of Chonbuk National University (CBNU 2018-052).

Consent for publication: Not applicable

Availability of data and materials: All of the data are available with reasonable request from the corresponding author.

Competing interests: No potential conflict of interest was reported by the authors.

Funding: This work was supported by the National Research Foundation of Korea (NRF) grant funded by the Korea government (MSIT). (No. 2018R1A2B6006477)

Authors' Contributions: HW performed the experiments drafted the manuscript. JEP designed the study and interpreted the results. YSC was the principal investigator.

Acknowledgement: Authors thank Yu-Jung Chang, PhD, Center for University-wide Research Facilities (CURF) at Jeonbuk National University, for helping in cryomicrotome.

Authors' information: Department of Food Science and Human Nutrition, Jeonbuk National University and Obesity Research Center, 567 Baekje-daero, Deokjin-gu, Jeonju-si, jeollabuk-do, 54896 Republic of Korea 


\section{References}

1. Jung YH. The life expectancy and health-adjusted life expectancy of Koreans. Health Welfare Policy Forum.2012;193:5-18.

2. Kotchen TA. Obesity-related hypertension: epidemiology, pathophysiology, and clinical management. Am J Hypertens. 2010;23:1170-8.

3. Kawarazaki W, Fujita T. The role of aldosterone in obesity-related hypertension. Am J Hypertens. 2016;29:415-23.

4. World Health Organization. Hypertension. 2019. Retrieved on September 2019 from https://www.who.int/news-room/fact-sheets/detail/hypertension.

5. Hall JE, do Carmo JM, da Silva AA, Wang Z, Hall ME. Obesity-induced hypertension: interaction of neurohumoral and renal mechanisms. Circ Res. 2015;116:991-1006.

6. Lu H, Boustany-Kari CM, Daugherty A, Cassis LA. Angiotensin II increases adipose angiotensinogen expression. Am J Physiol Endocrinol Metab. 2007;292:E1280-7.

7. Rüster $\mathrm{C}$, Wolf $\mathrm{G}$. The role of the renin-angiotensin-aldosterone system in obesity-related renal diseases. Semin Nephrol. 2013;33:44-53.

8. Schunkert $H$, Ingelfinger JR, Hirsch AT, Pinto Y, Remme WJ, Jacob H, et al. Feedback regulation of angiotensin converting enzyme activity and mRNA levels by angiotensin II. Circ Res. 1993;72:312-8.

9. Frigolet ME, Torres N, Tovar AR. The renin-angiotensin system in adipose tissue and its metabolic consequences during obesity. J Nutr Biochem. 2013;24:2003-15.

10. Kwak CS, Park SC, Song KY. Doenjang, a fermented soybean paste, decreased visceral fat accumulation and adipocyte size in rats fed with high fat diet more effectively than nonfermented soybeans. J Med Food.2012;15:1-9.

11. Shin D, Jeong D. Korean traditional fermented soybean products: Jang. J Ethn Foods. 2015;2:2-7.

12. Cha YS, Park Y, Lee M, Chae SW, Park K, Kim Y, et al. Doenjang, a Korean fermented soy food, exerts antiobesity and antioxidative activities in overweight subjects with the PPAR- $\gamma 2$ C1431T polymorphism: 12-week, double-blind randomized clinical trial. J Med Food. 2014;17:119-27.

13. Jang SE, Kim KA, Han MJ, Kim DH. Doenjang, a fermented Korean soybean paste, inhibits lipopolysaccharide production of gut microbiota in mice. J Med Food. 2014;17:67-75.

14. Kochanek KD, Xu JQ, Murphy SL, Minino AM, Kung HC. Deaths: final data for 2009. Nat Vital Stat Rep.2011;60: 1-167.

15. Bae CR, Kwon DY, Cha YS. Anti-obesity effects of salted and unsalted Doenjang supplementation in C57BL/6J mice fed with high fat diet. J Korean Soc Food Sci Nutr. 2013;42:1036-42.

16. Mun EG, Sohn HS, Kim MS, Cha YS. Antihypertensive effect of Ganjang (traditional Korean soy sauce) on Sprague-Dawley Rats. Nutr Res Pract. 2017;11:388-95.

17. Mun EG, Park J.E, Cha YS. Effects of Doenjang, a Traditional Korean Soybean Paste, with High-Salt Diet on Blood Pressure in Sprague-Dawley Rats. Nutrients. 2019;11:2745. 
18. Segovia SA, Vickers MH, Harrison CJ, Patel R, Gray C, Reynolds CM. Maternal high-fat and high-salt diets have differential programming effects on metabolism in adult male rat offspring. Front Nutr. 2018;5:1.

19. Ofei F. Obesity-a preventable disease. Ghana Medical J. 2005;39:98.

20. He FJ, MacGregor GA. Plasma sodium and hypertension. Kidney Int. 2004;66: 2454-66.

21. Weidemann BJ, Voong S, Morales-Santiago FI, Kahn MZ, Ni J, Littlejohn NK, et al. Dietary sodium suppresses digestive efficiency via the renin-angiotensin system. Sci. Rep. 2015;5:11123.

22. Moriyama T, Kishimoto K, Nagai K, Urade R, Ogawa T, Utsumi S, et al. Soybean $\beta$-conglycinin diet suppresses serum triglyceride levels in normal and genetically obese mice by induction of $\beta$-oxidation, downregulation of fatty acid synthase, and inhibition of triglyceride absorption. Biosci Biotechnol Biochem. 2004;68:352-9.

23. Gu JW, Young E, Pan ZJ, Tucker KB, Shparago M, Huang M, et al. Long-term high salt diet causes hypertension and alters renal cytokine gene expression profiles in Sprague-Dawley rats. Beijing Da Xue Xue Bao Yi Xue Ban. 2009;41:505-15.

24. Maleki Varnosfaderani S, Razavi SH, Fadda AM. Germination and Fermentation of Soybeans: Two Healthy Steps to Release Angiotensin Converting Enzyme Inhibitory Activity Compounds. Appl Food Biotechnol. 2019;6(4):201-15.

25. Thomas MC, Tikellis C. Losing control: positive and negative feedback in the renin angiotensin system. Curr. Hypertens Rev. 2009;5:222-6.

26. Thatcher S, Yiannikouris F, Gupte M, Cassis L. The adipose renin-angiotensin system: role in cardiovascular disease. Mol Cell Endocrinol. 2009;302:111-7.

27. Kim S, Soltani-Bejnood M, Quignard-Boulange A, Massiera F, Teboul M, Ailhaud G, et al. The adipose renin-angiotensin system modulates systemic markers of insulin sensitivity and activates the intrarenal renin-angiotensin system. J Biomed Biotechnol.2006;2006(5):27012.

28. Kalupahana NS, Moustaid-Moussa N. The renin-angiotensin system: a link between obesity, inflammation and insulin resistance.Obes Rev. 2012;13:136-49.

29. Frantz EDC, Prodel E, Braz ID, Giori IG, Bargut TCL, Magliano DAC, et al. Modulation of the reninangiotensin system in white adipose tissue and skeletal muscle: focus on exercise training. Clin. Sci. 2018;132:1487-507.

30. Massiéra F, Bloch-Faure M, Ceiler D, Murakami K, Fukamizu A, Gasc JM, et al. Adipose angiotensinogen is involved in adipose tissue growth and blood pressure regulation. FASEB J. 2001;15:2727-9.

31. Ong FS, Bernstein KE, Rotter JI. Genetics of Blood Pressure Regulation. Emery and Rimoin's Principles and Practice of Medical Genetics. 2013; 1-22.

32. Shao W, Seth DM, Prieto MC, Kobori H, Navar LG. Activation of the renin-angiotensin system by a lowsalt diet does not augment intratubular angiotensinogen and angiotensin II in rats. Am J Physiol Renal Physiol. 2012;304:F505-14. 
33. Van Rooyen JM, Poglitsch M, Huisman HW, Mels C, Kruger R, Malan L, et al. Quantification of systemic renin-angiotensin system peptides of hypertensive black and white African men established from the RAS-Fingerprint ${ }^{\circledR}$. J Renin Angiotensin Aldosterone Syst. 2016;17:1470320316669880.

34. Schricker K, Holmer S, Hamann M, Riegger G, Kurtz A. Interrelation between renin mRNA levels, renin secretion, and blood pressure in two-kidney, one clip rats. Hypertension 1994;24:157-62.

35. Tank JE, Henrich WL, Moe OW. Regulation of glomerular and proximal tubule renin mRNA by chronic changes in dietary $\mathrm{NaCl}$. Am J Physiol Renal Physiol. 1997;273:F892-8.

36. Oshima Y, Morimoto S, Ichihara A. Roles of the (pro) renin receptor in the kidney. World J Nephrol. 2014;3:302.

37. Neubauer B, Schrankl J, Steppan D, Neubauer K, Sequeira-Lopez ML, Pan L, et al. Angiotensin II shortloop feedback: is there a role of Ang II for the regulation of the renin system in vivo?. Hypertension 2018;71:1075-82.

38. Wei CC, Tian B, Perry G, Meng QC, Chen YF, Oparil S, et al. Differential ANG II generation in plasma and tissue of mice with decreased expression of the ACE gene. Am J Physiol Heart Circ Physiol. 2002;282:H2254-8.

39. Dong T, Chen JW, Tian LL, Wang LH, Jiang R.D, Zhang Z, et al. Role of the renin-angiotensin system, renal sympathetic nerve system, and oxidative stress in chronic foot shock-induced hypertension in rats. Int J Biol Sci. 2015;11:652.

40. Yim HE, Yoo KH. Renin-Angiotensin system-considerations for hypertension and kidney. Electrolyte Blood Press. 2008;6:42-50.

41. Carey RM. Newly discovered components and actions of the renin-angiotensin system. Hypertension. 2013;62:818-22.

42. White PC. Aldosterone synthase deficiency and related disorders.Mol Cell Endocrinol. 2004;217:81-7.

43. Le Menuet D, Isnard R, Bichara M, Viengchareun S, Muffat-Joly M, Walker F, et al. Alteration of cardiac and renal functions in transgenic mice overexpressing human mineralocorticoid receptor. $\mathrm{J}$ Biol Chem. 2001;276:38911-20.

44. Denton KM, Fennessy PA, Alcorn DAINE, Anderson WP. Morphometric analysis of the actions of angiotensin II on renal arterioles and glomeruli. Am J Physiol Renal Physiol. 1992;262:F367-72.

45. Gomes PM, Sá RWM, Aguiar GL, Paes MHS, Alzamora AC, Lima WG, et al. Chronic high-sodium diet intake after weaning lead to neurogenic hypertension in adult Wistar rats. Sci. Rep. 2017;7:5655.

46. Koo H, Hwang S, Kim TH, Kang SW, Oh KH, Ahn C, et al. The ratio of urinary sodium and potassium and chronic kidney disease progression: Results from the KoreaN Cohort Study for Outcomes in Patients with Chronic Kidney Disease (KNOW-CKD). Medicine. 2018;97.

47. Wang Y, Xie BQ, Gao WH, Yan DY, Zheng WL, Lv YB, et al. Effects of renin-angiotensin system inhibitors on renal expression of renalase in Sprague-Dawley rats fed with high salt diet. Kidney Blood Press Res. 2015;40:605-13.

\section{Tables}


Table 1 The composition of experimental diets

\begin{tabular}{|lllll|}
\hline Ingredient & ND & HD & HDS & HDJ \\
\hline Casein & 20 & 25.85 & 23.96 & 22.93 \\
\hline L-Cystine & 0.3 & 0.39 & 0.36 & 0.34 \\
\hline Corn Starch & 15 & 0 & 0 & 0 \\
\hline Maltodextrin & & 16.15 & 14.97 & 14.33 \\
\hline Sucrose & 50 & 8.89 & 8.24 & 7.89 \\
\hline Cellulose & 5 & 6.46 & 5.99 & 5.73 \\
\hline Corn/Soybean Oil & 5 & 3.23 & 2.99 & 2.87 \\
\hline Lard & & 31.66 & 29.35 & 28.08 \\
\hline Mineral Mix & 3.5 & 1.29 & 1.20 & 1.15 \\
\hline DiCalcium Phosphate & & 1.68 & 1.56 & 1.49 \\
\hline Calcium Carbonate & & 0.71 & 0.66 & 0.63 \\
\hline Potassium Citrate & & 2.13 & 1.98 & 1.89 \\
\hline Vitamin Mix & 1 & 1.29 & 1.20 & 1.15 \\
\hline Choline Bitartrate & 0.2 & 0.26 & 0.24 & 0.23 \\
\hline NaCl (Table salt) & & & 7.3 & 6.3 \\
\hline Dried doenjang & & & & 5 \\
\hline total & 100 & 100 & 100 & 100 \\
\hline kcal/g & 3.9 & 5.24 & 4.86 & 4.82 \\
\hline
\end{tabular}

ND; AIN76A, Research Diets, Inc. New Brunswick, NJ, USA), (HD; 60\% kcal\% fat, D12492, Research Diets, New Brunswick, NJ, USA), (HDS; HD + 8\% table salt), (HDJ; HD + Doenjang containing 8\% table salt

Table 2 Sequences of primers used for PCR 


\begin{tabular}{|lll|}
\hline Gene & Forward & Reverse \\
\hline Ppary & ACCACTCGCATTCCTTTGAC & CCACAGACTCGGCACTCAAT \\
\hline Adiponectin & GCACACCAAAACCCTCATCA & TCATTGGCTATCTGCAGCAC \\
\hline Agt & GATGCGCACAAGGTCCTG & CAGGGTGCTGTCCACACTGGCTCGC \\
\hline renin & TTCTCTCCCAGAGGGTGCTA & CCCTCCTCACACAACAAGGT \\
\hline Ace & GAGCCATCCTTCCCTTTTTC & GGCTGCAGCTCCTGGTATAG \\
\hline Agtr1 & ACTCTTTCCTACCGCCCTTC & TTAGCCCAAATGGTCCTCTG \\
\hline Agtr2 & GAAGGACAACTTCAGTTTTGC & CAAGGGGAACTACATAAGATGC \\
\hline Star & GACCAGCCCATGGACAGACTC & AGGTCAATAGTGAGCAGCCA \\
\hline Hsd3b1 & ATGCCCAGTACCTGAGGAGA & TTGAGGGCCGCAAGTATCA \\
\hline Cyp11a1 & AGAAGCTGGGCAACATGGAGTCAG & TCACATCCCAGGCAGCTGCATGGT \\
\hline Cyp21 & CATCGTGCAACTAAGGCTAG & TGGAAGGGAGGATTAAGAG \\
\hline MR & GCTTTGATGGTAGCTGCG & TGAGCACCAATCCGGTAG \\
\hline Renalase & TGACCTTGTCATCCTCACCA & AACTCCAAATGGGACAGTGG \\
\hline B-actin & AGCCTTCCTTCTTGGGTATGG & CACTTGCGGTGCACGGTATGG \\
\hline
\end{tabular}

Ppary, Peroxisome proliferator-activated receptor-gamma; Agt, Angiotensinogen; Ace, Angiotensinconverting enzyme; Agtr1, Angiotensin II receptor type 1; Agtr2, Angiotensin II receptor type 2; Star, Steroidogenic acute regulatory protein; $H s d 3 b 1,3 \beta$-Hydroxysteroid dehydrogenase type 1; Cyp11a1, Cholesterol side-chain cleavage enzyme; Cyp21, 21-Hydroxylase; $M R$, Mineralocorticoid receptor.

Table 3 Body weight, diet intake, and blood glucose in rat

\begin{tabular}{|lllll|}
\hline & $\begin{array}{l}\text { Initial Body Weight } \\
(\mathbf{g})\end{array}$ & Final Body Weight $(\mathbf{g})$ & $\begin{array}{l}\text { Diet Intake } \\
(\mathbf{g} / \text { day })\end{array}$ & Blood Glucose Level (mg/dL) \\
\hline ND & $202.95 \pm 5.47^{\text {ns }}$ & $509.03 \pm 10.88^{\mathrm{c}}$ & $19.99 \pm 0.39^{\mathrm{a}}$ & $89.83 \pm 2.36^{\mathrm{a}}$ \\
\hline HD & $201.82 \pm 3.51^{\mathrm{ns}}$ & $633.27 \pm 17.20^{\mathrm{a}}$ & $17.73 \pm 0.46^{\mathrm{b}}$ & $93.8 \pm 4.19^{\mathrm{a}}$ \\
\hline HDS & $195.43 \pm 8.61^{\mathrm{ns}}$ & $558.65 \pm 9.58^{\mathrm{b}}$ & $17.02 \pm 0.46^{\mathrm{b}}$ & $90.33 \pm 1.89^{\mathrm{a}}$ \\
\hline HDJ & $200.9 \pm 4.73^{\mathrm{ns}}$ & $548.48 \pm 6.41^{\mathrm{bc}}$ & $17.37 \pm 0.42^{\mathrm{b}}$ & $80.13 \pm 2.86^{\mathrm{b}}$ \\
\hline
\end{tabular}

Values are given as mean \pm SEM. Values with different superscripts in the same column are significantly different $(p<0.05)$ by Duncan's multiple range test $(a>b ; n s$, not significant). Six rats were assigned to 
each group. ND; normal diet group, HD; high-fat diet group, HDS; high-fat diet with salt group, HDJ; high-fat diet with doenjang group.

Table $4 \mathrm{Na}^{+}$and $\mathrm{K}^{+}$levels of urine, feces, and serum in rats.

\begin{tabular}{|c|c|c|c|c|c|c|c|c|}
\hline & \multicolumn{3}{|c|}{ Urine (ppm) } & \multicolumn{3}{|c|}{ Feces (ppm) } & \multicolumn{2}{|c|}{ Serum $(\mathrm{mEq} / \mathrm{L})$} \\
\hline & $\mathrm{Na}^{+}$ & $\mathrm{K}^{+}$ & $\mathrm{Na}^{+} / \mathrm{K}^{+}$ & $\mathrm{Na}^{+}$ & $\mathrm{K}^{+}$ & $\mathrm{Na}^{+} / \mathrm{K}^{+}$ & $\mathrm{Na}^{+}$ & $\mathrm{K}^{+}$ \\
\hline ND & $\begin{array}{l}1845.86 \pm \\
134.35^{d}\end{array}$ & $\begin{array}{l}4929.48 \pm \\
461.13^{b}\end{array}$ & $\begin{array}{l}0.42 \pm \\
0.02^{c}\end{array}$ & $\begin{array}{l}504.08 \pm \\
41.96^{\text {ns }}\end{array}$ & $\begin{array}{l}1098.18 \pm \\
100.55^{\mathrm{a}}\end{array}$ & $\begin{array}{l}0.48 \pm \\
0.37^{c}\end{array}$ & $134.7 \pm 0.85^{b}$ & $\begin{array}{l}4.34 \pm \\
0.11^{b}\end{array}$ \\
\hline HD & $\begin{array}{l}2431.53 \pm \\
158.41^{c}\end{array}$ & $\begin{array}{l}12571.03 \pm \\
469.02^{\mathrm{a}}\end{array}$ & $\begin{array}{l}0.19 \pm \\
0.01^{d}\end{array}$ & $\begin{array}{l}548.99 \pm \\
98.73^{\text {ns }}\end{array}$ & $\begin{array}{l}728.30 \pm \\
68.08^{b}\end{array}$ & $\begin{array}{l}0.43 \pm \\
0.42^{c}\end{array}$ & $138.3 \pm 1.31^{\mathrm{a}}$ & $\begin{array}{l}5.43 \pm \\
0.17^{\mathrm{a}}\end{array}$ \\
\hline HDS & $\begin{array}{l}9315.33 \pm \\
32.78^{a}\end{array}$ & $\begin{array}{l}1870.31 \pm \\
67.18^{d}\end{array}$ & $\begin{array}{l}4.46 \pm \\
0.00^{a}\end{array}$ & $\begin{array}{l}568.70 \pm \\
2.70^{\text {ns }}\end{array}$ & $\begin{array}{l}462.66 \pm \\
39.11^{c}\end{array}$ & $\begin{array}{l}1.59 \pm \\
0.60^{\mathrm{a}}\end{array}$ & $\begin{array}{l}137.5 \pm \\
0.43^{\mathrm{ab}}\end{array}$ & $\begin{array}{l}5.62 \pm \\
0.12^{\mathrm{a}}\end{array}$ \\
\hline HDJ & $\begin{array}{l}9426.76 \pm \\
36.69^{a}\end{array}$ & $\begin{array}{l}2183.75 \pm \\
64.67^{c}\end{array}$ & $\begin{array}{l}3.83 \pm \\
0.00^{b}\end{array}$ & $\begin{array}{l}614.53 \pm \\
2.47^{\mathrm{ns}}\end{array}$ & $\begin{array}{l}828.92 \pm \\
36.06^{b}\end{array}$ & $\begin{array}{l}0.84 \pm \\
0.77^{\mathrm{b}}\end{array}$ & $136.8 \pm 1.05^{\mathrm{ab}}$ & $\begin{array}{l}4.72 \pm \\
0.21^{\mathrm{b}}\end{array}$ \\
\hline
\end{tabular}

Values are given as mean \pm SEM. Values with different superscripts in the same column are significantly different $(p<0.05)$ by Duncan's multiple range test $(a>b ; n s$, not significant). Six rats were assigned to each group. ND; normal diet group, HD; high-fat diet group, HDS; high-fat diet with salt group, HDJ; high-fat diet with doenjang group.

\section{Figures}




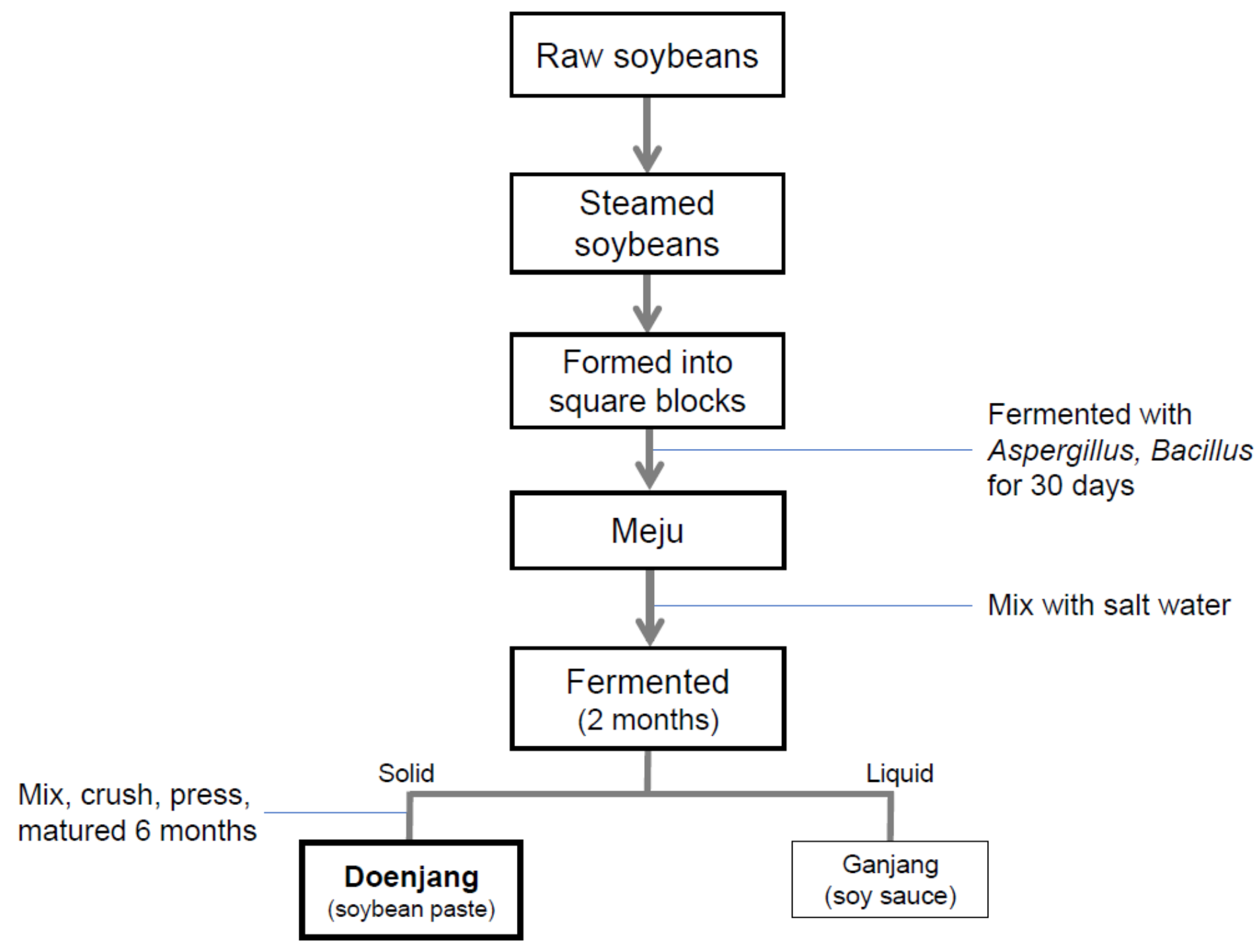

Figure 1

Manufacturing process diagram for Doenjang. 


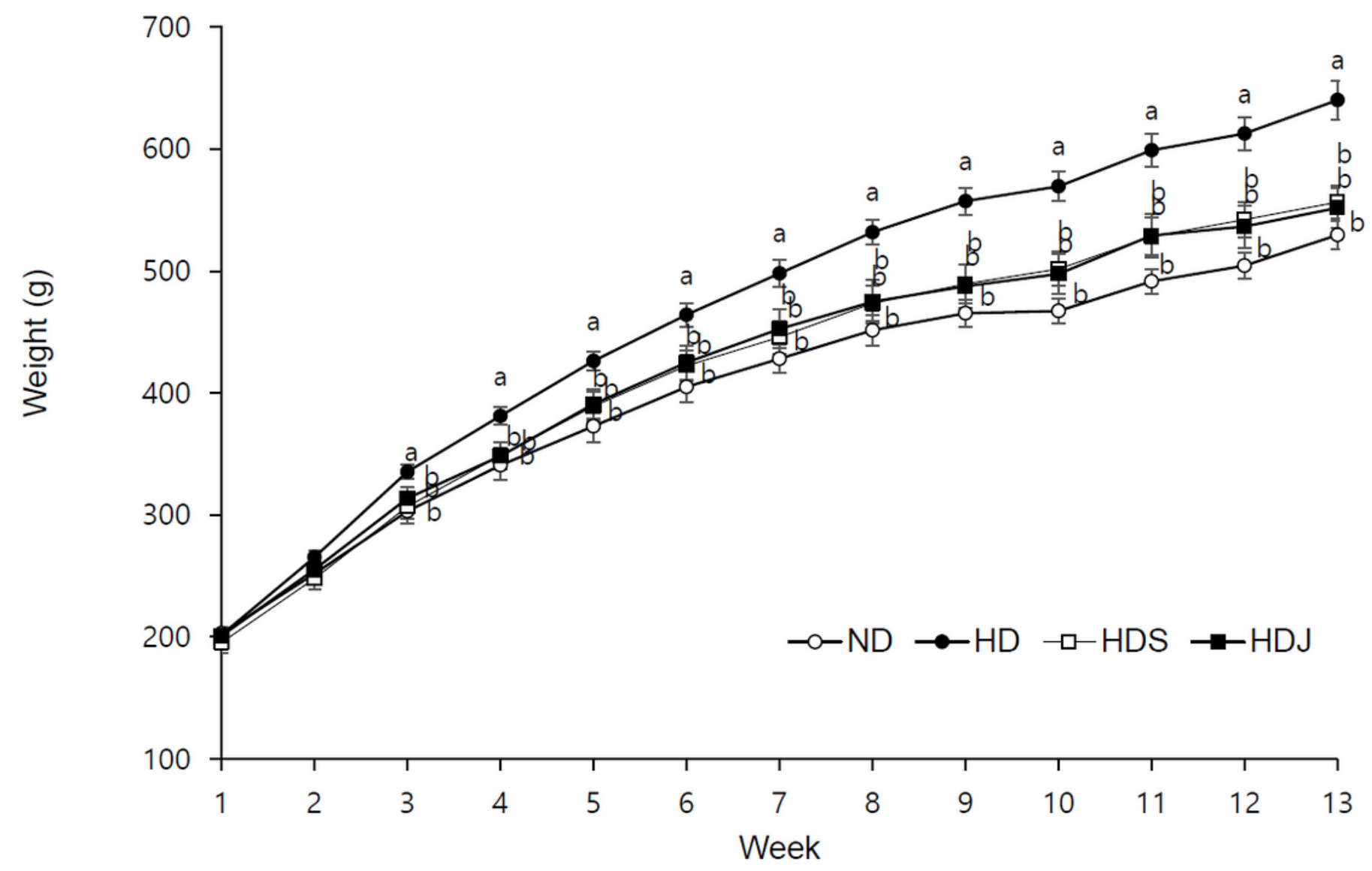

Figure 2

Growth curve of body weight. Body weight growth curve of the four groups of rats. The body weights of each group of rats recorded weekly are shown. Values are the mean \pm SEM, with different letters significantly different $(p<0.05)$ by Duncan's multiple range test $(a>b)$. Six rats were assigned to each group. ND; normal diet group, HD; high-fat diet group, HDS; high-fat diet with salt group, HDJ; high-fat diet with doenjang group. 
(a)

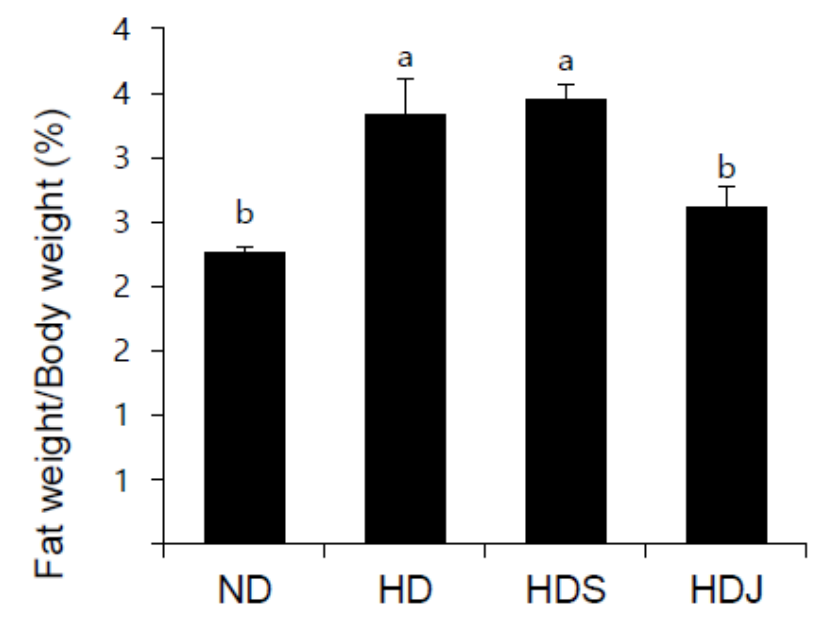

(c)

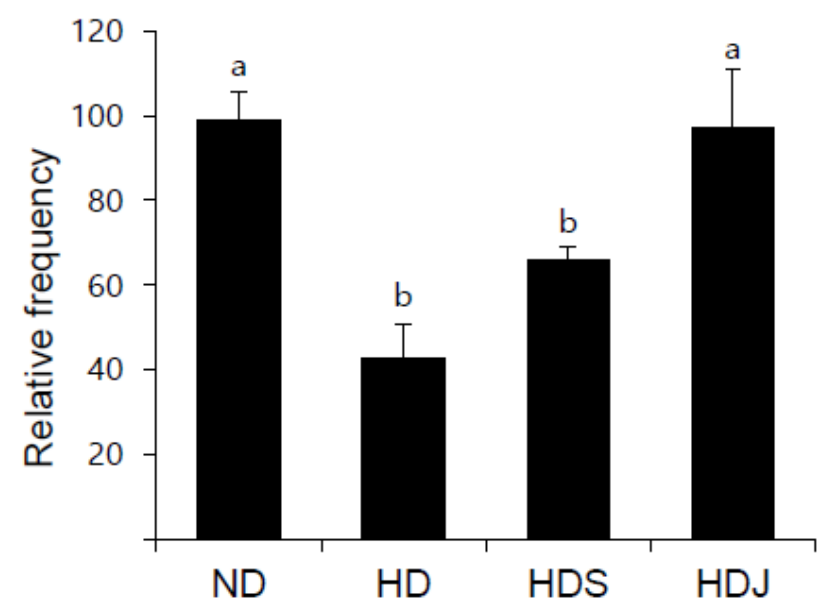

(b)
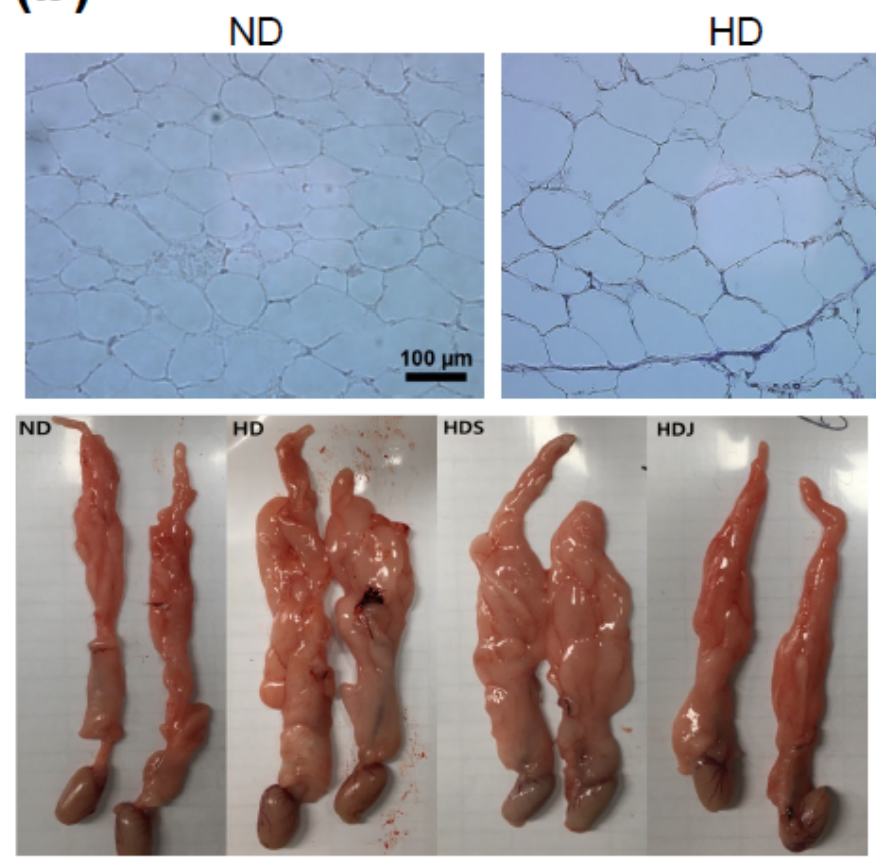

HDS

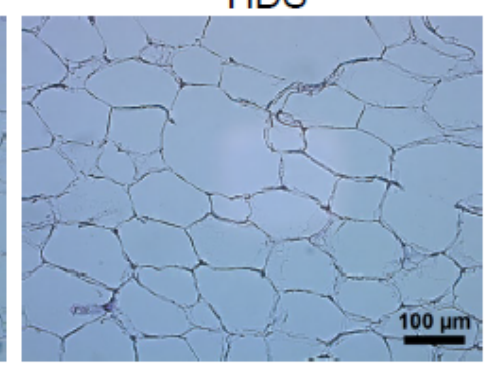

HDJ

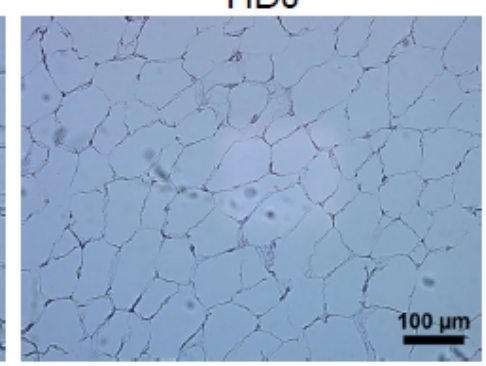

\section{Figure 3}

Epididymal fat weight and size of adipocyte in rats. (a) Epididymal fat-to-BW ratio (\%), (b) pictures of representative gross epididymal fat and histology of fat section, (c) the ratio of the number of adipocytes to area. Values are given as mean \pm SEM. Values with different superscripts are significantly different $(p<$ $0.05)$ by ANOVA with Duncan's multiple range test $(a>b)$. Six rats were assigned to each group. ND; normal diet group, HD; high-fat diet group, HDS; high-fat diet with salt group, HDJ; high-fat diet with doenjang group. 


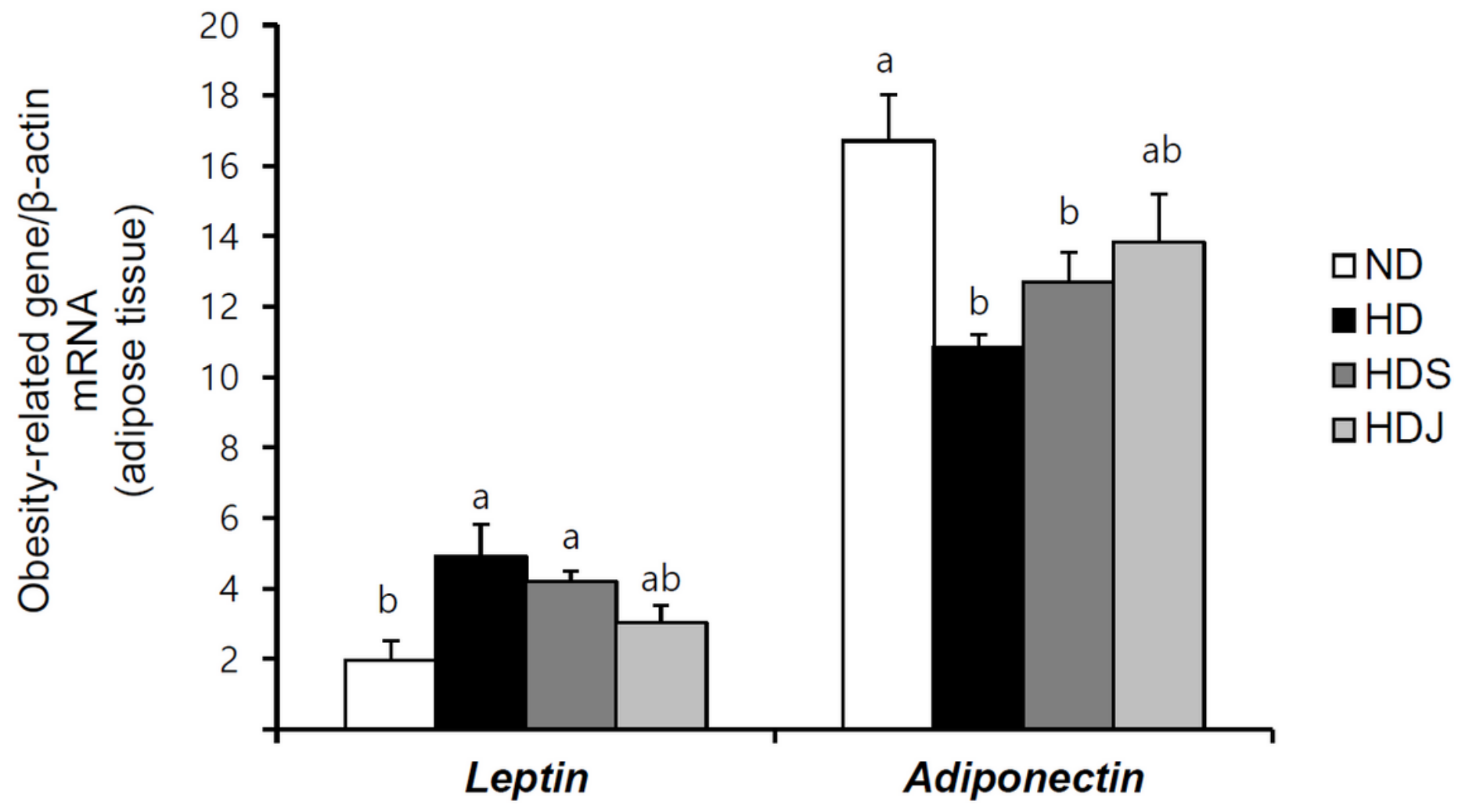

Figure 4

Expression of Obesity-related genes in epididymal fat. Values are given as mean \pm SEM. Values with different superscripts are significantly different $(p<0.05)$ by ANOVA with Duncan's multiple range test $(a>$ b). Six rats were assigned to each group. ND; normal diet group, HD; high-fat diet group, HDS; high-fat diet with salt group, HDJ; high-fat diet with doenjang group. 


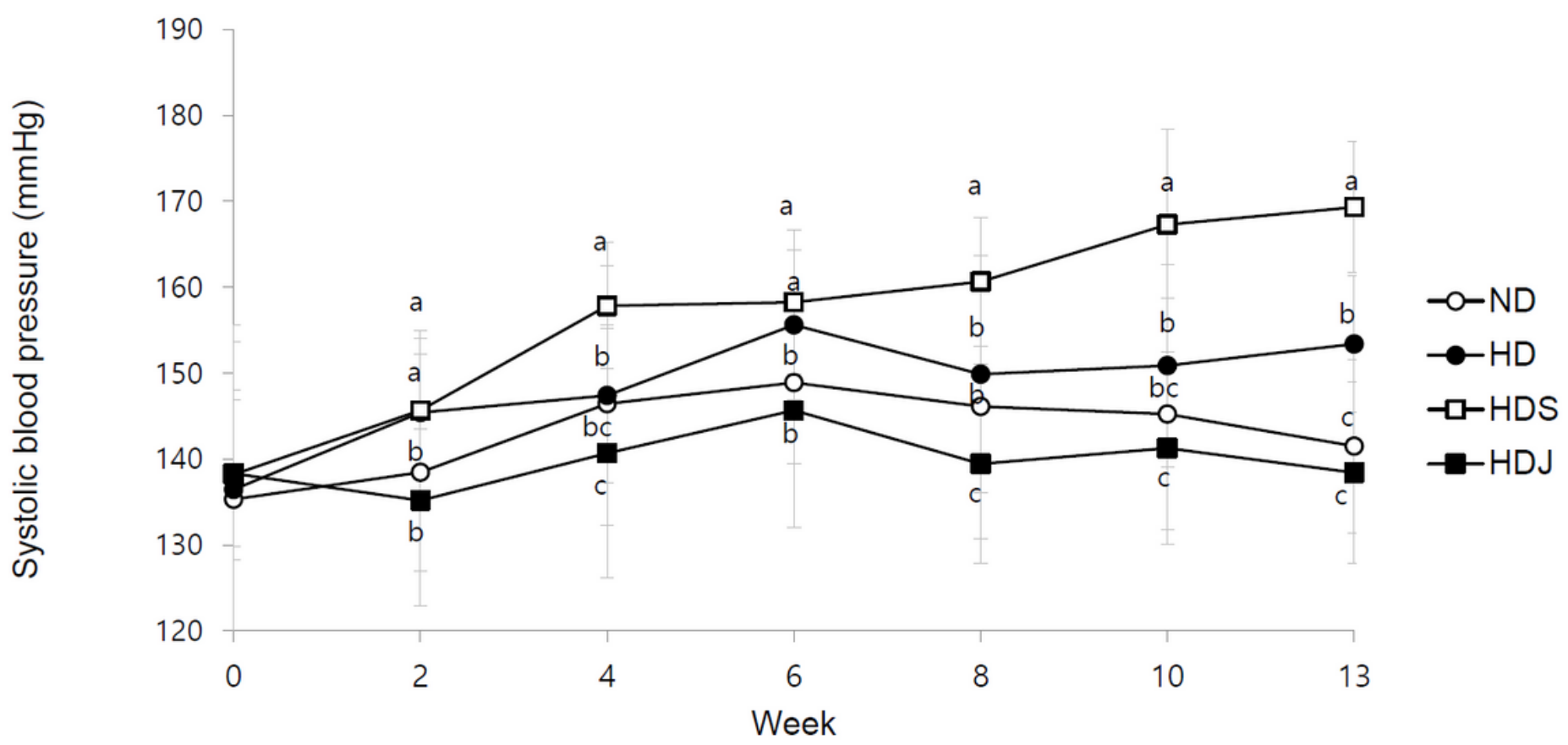

\section{Figure 5}

Systolic blood pressure for experimental period. Systolic blood pressure curve of the four groups of rats. The blood pressure of each group of rats recorded alternate weeks are shown. Values are the mean \pm SD, with different letters significantly different $(p<0.05)$ by Duncan's multiple range test $(a>b)$. Six rats were assigned to each group. ND; normal diet group, HD; high-fat diet group, HDS; high-fat diet with salt group, HDJ; high-fat diet with doenjang group.
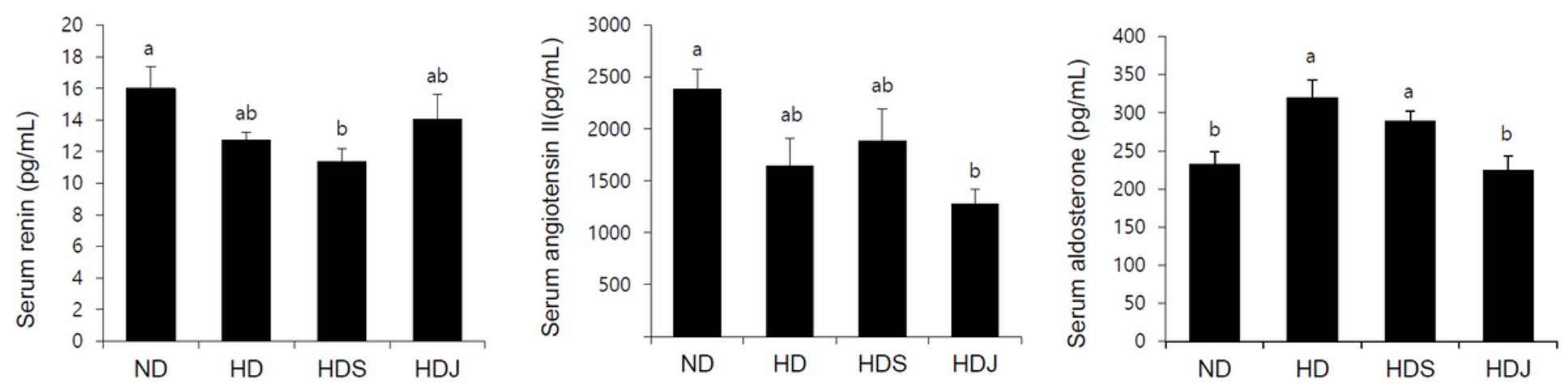

Figure 6

Renin, angiotensin II, and aldosterone levels in serum. Values are given as mean \pm SEM. Values with different superscripts are significantly different $(p<0.05)$ by ANOVA with Duncan's multiple range test $(a>$ b). Six rats were assigned to each group. ND; normal diet group, HD; high-fat diet group, HDS; high-fat diet with salt group, HDJ; high-fat diet with doenjang group. 
Agt

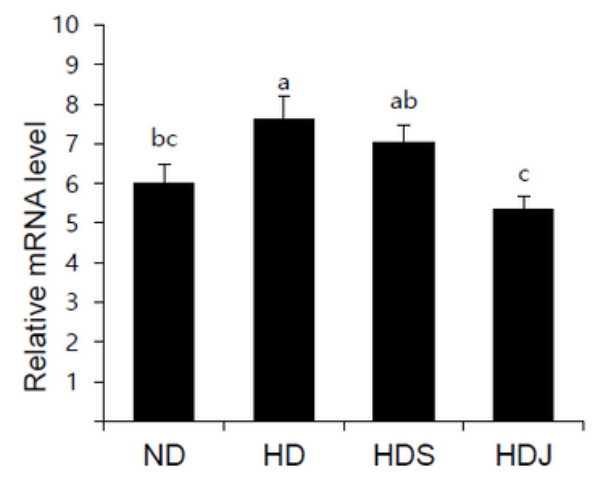

Agtr1

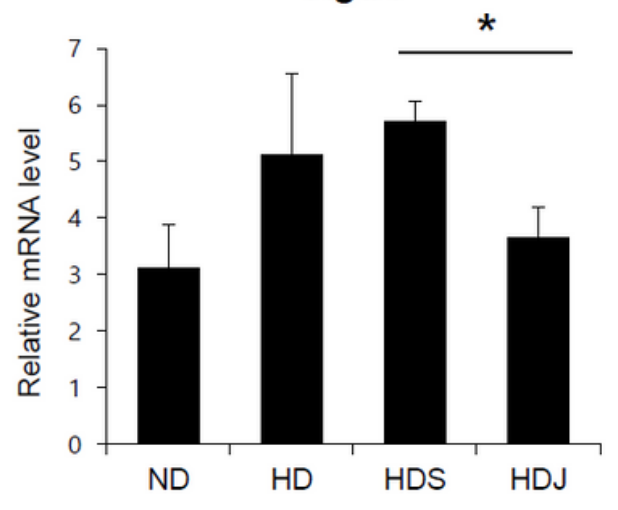

renin

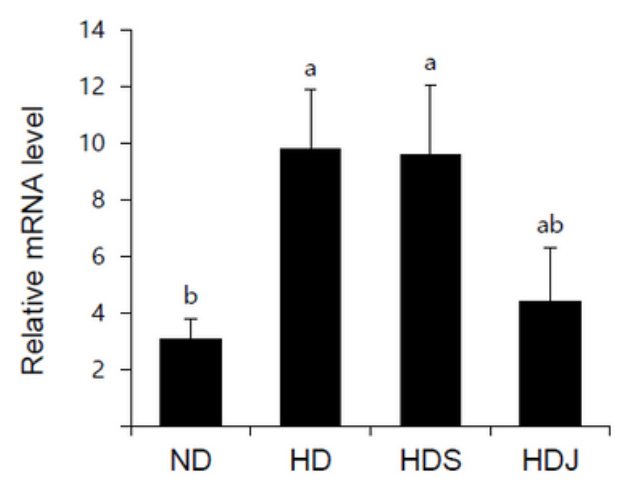

Agtr2

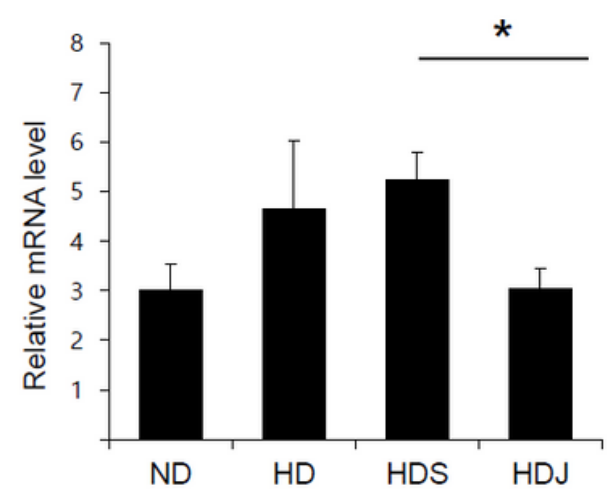

Figure 7

Effect of doenjang treatment on mRNA levels of RAS-related genes in white adipose tissue of rats. Values are given as mean \pm SEM. Values with different superscripts are significantly different $(p<0.05)$ by ANOVA with Duncan's multiple range test $(a>b)$. ${ }^{*} p<0.05$ for HDS versus HDJ. Six rats were assigned to each group. Six rats were assigned to each group. ND; normal diet group, HD; high-fat diet group, HDS; high-fat diet with salt group, HDJ; high-fat diet with doenjang group. Agt; Angiotensinogen, Ace; Angiotensinconverting enzyme, Agtr1; Angiotensin II receptor type 1, Agtr2; Angiotensin II receptor type 2. 
Hepatic Agt

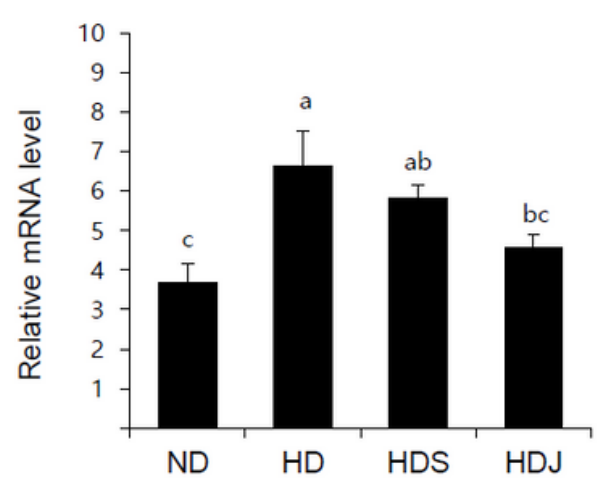

Renal Agtr1

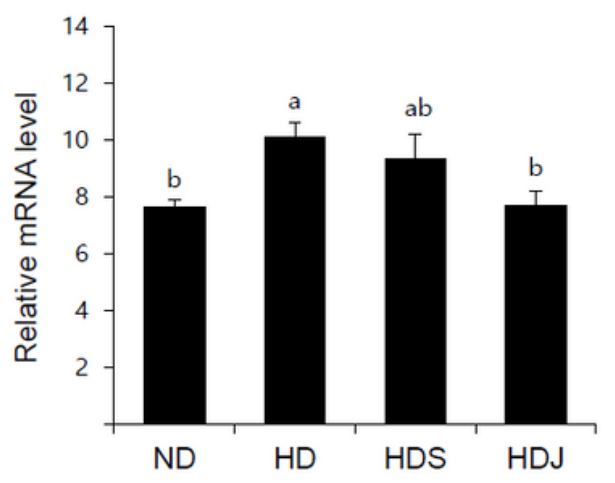

Renal renin

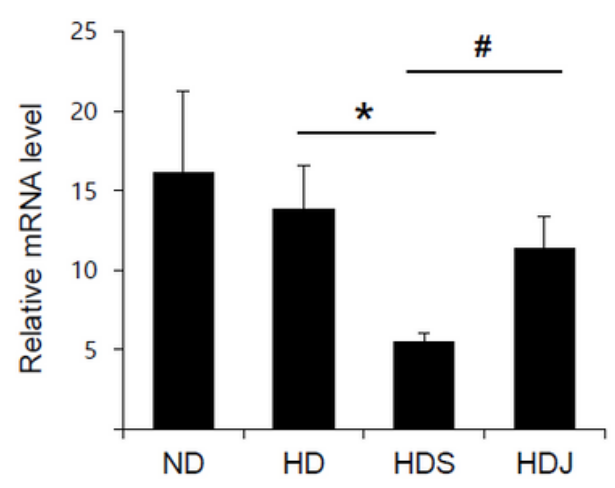

Renal Agtr2

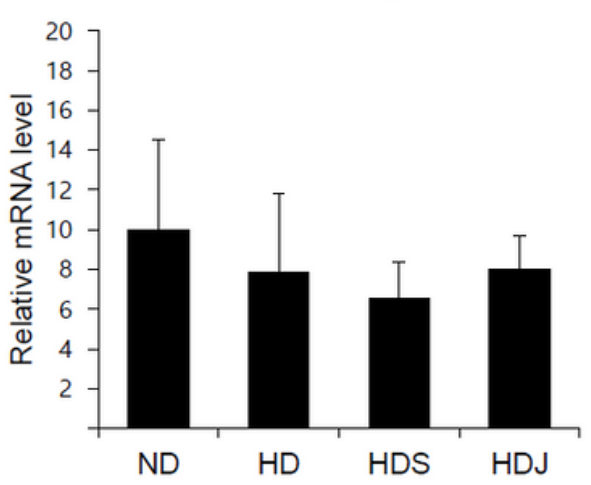

Renal Ace

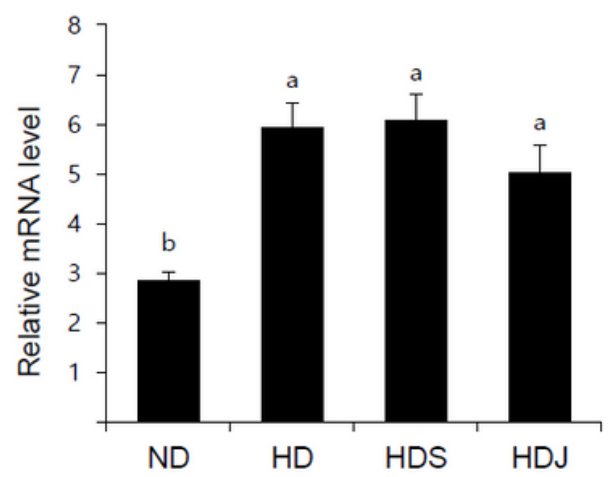

\section{Figure 8}

Effect of doenjang treatment on mRNA levels of RAS-related genes in liver and kidney of rats. Values are given as mean \pm SEM. Values with different superscripts are significantly different $(p<0.05)$ by ANOVA with Duncan's multiple range test $(a>b)$. ${ }^{*} p<0.05$ for HD versus HDS, $\# p<0.05$ for HDS versus HDJ. Six rats were assigned to each group. Six rats were assigned to each group. ND; normal diet group, HD; high-fat diet group, HDS; high-fat diet with salt group, HDJ; high-fat diet with doenjang group. Agt; Angiotensinogen, Ace; Angiotensin-converting enzyme, Agtr1; Angiotensin II receptor type 1, Agtr2; Angiotensin II receptor type 2. 
(a)

\section{Kidney}

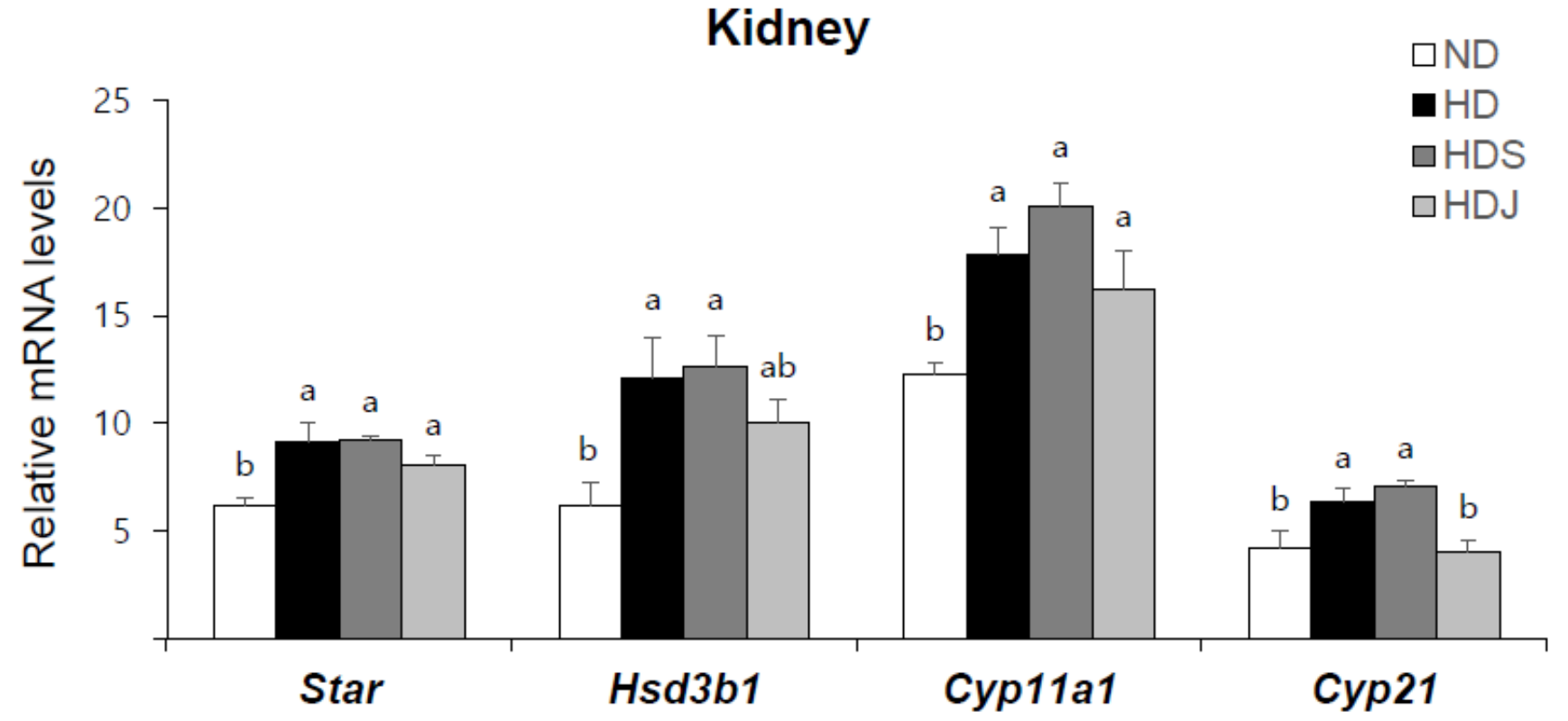

(b)

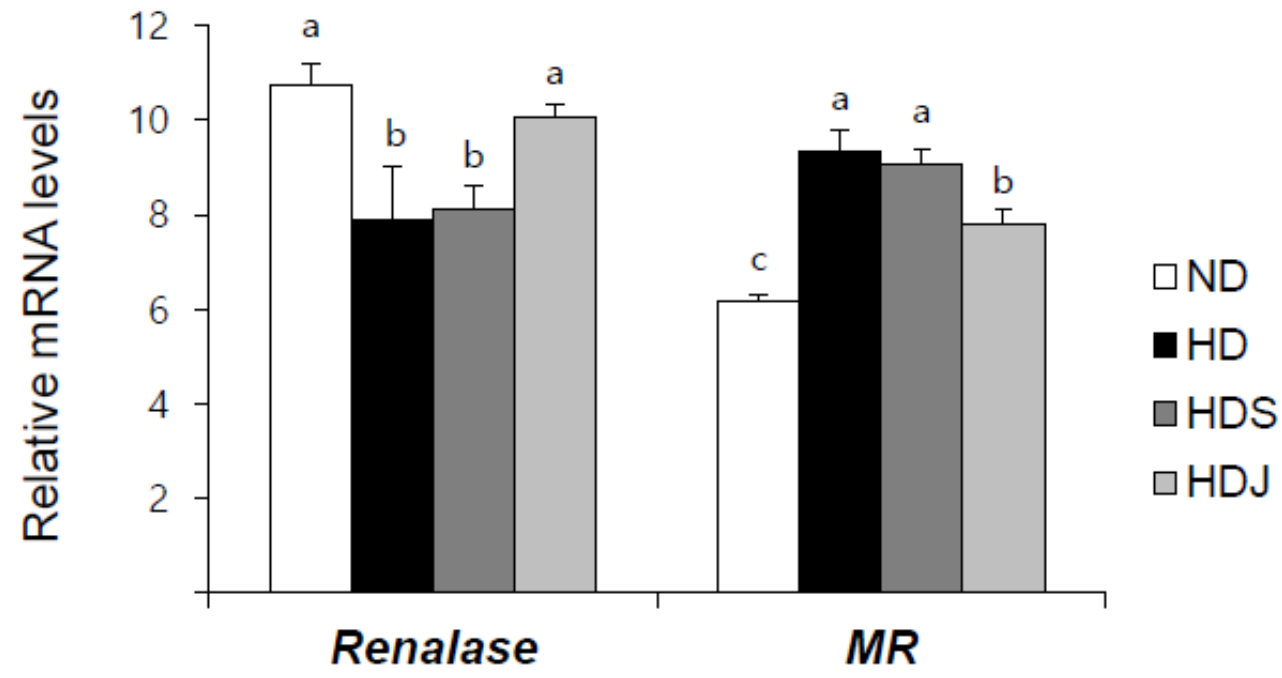

Figure 9

mRNA levels of Aldosterone related genes in kidney. (a) Aldosterone releasing factors, (b) MR and Renalase mRNA levels. Values are given as mean \pm SEM. Values with different superscripts are significantly different $(p<0.05)$ by ANOVA with Duncan's multiple range test $(a>b)$. Six rats were assigned to each group. ND; normal diet group, HD; high-fat diet group, HDS; high-fat diet with salt group, HDJ; high-fat diet with doenjang group. Star; Steroidogenic Acute Regulatory Protein, Hsd3b1; 3ß-hydroxysteroid dehydrogenase type 1, Cyp11a1; cholesterol side-chain cleavage enzyme, Cyp21; 21-hydroxylase, MR; Mineralocorticoid receptor. 

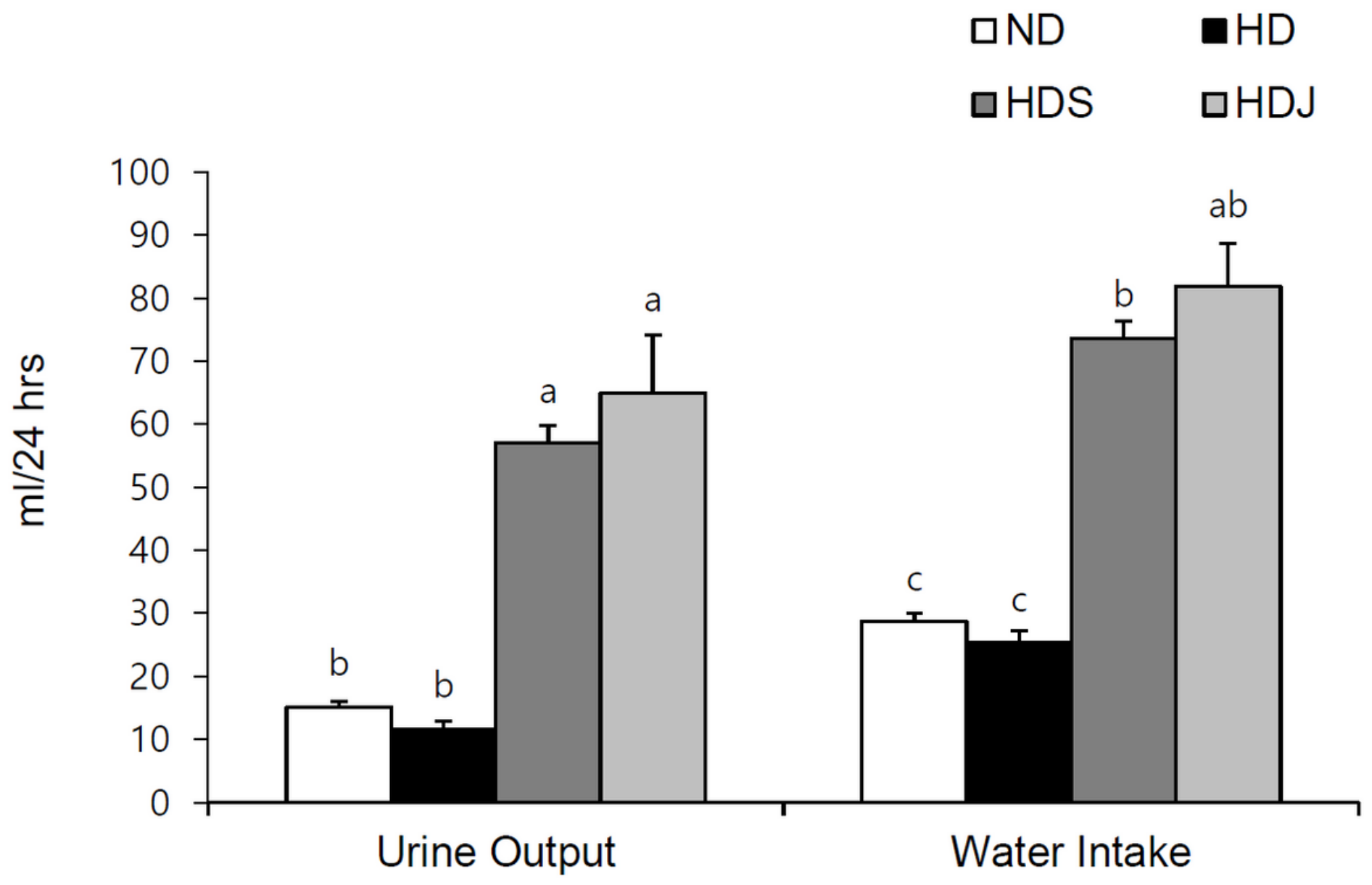

Figure 10

Urine output and water intake in $24 \mathrm{~h}$ metabolic cages. Values are given as mean $\pm \mathrm{SEM}$. Values with different superscripts are significantly different $(p<0.05)$ by ANOVA with Duncan's multiple range test $(a>$ b). Six rats were assigned to each group. ND; normal diet group, HD; high-fat diet group, HDS; high-fat diet with salt group, HDJ; high-fat diet with doenjang group.
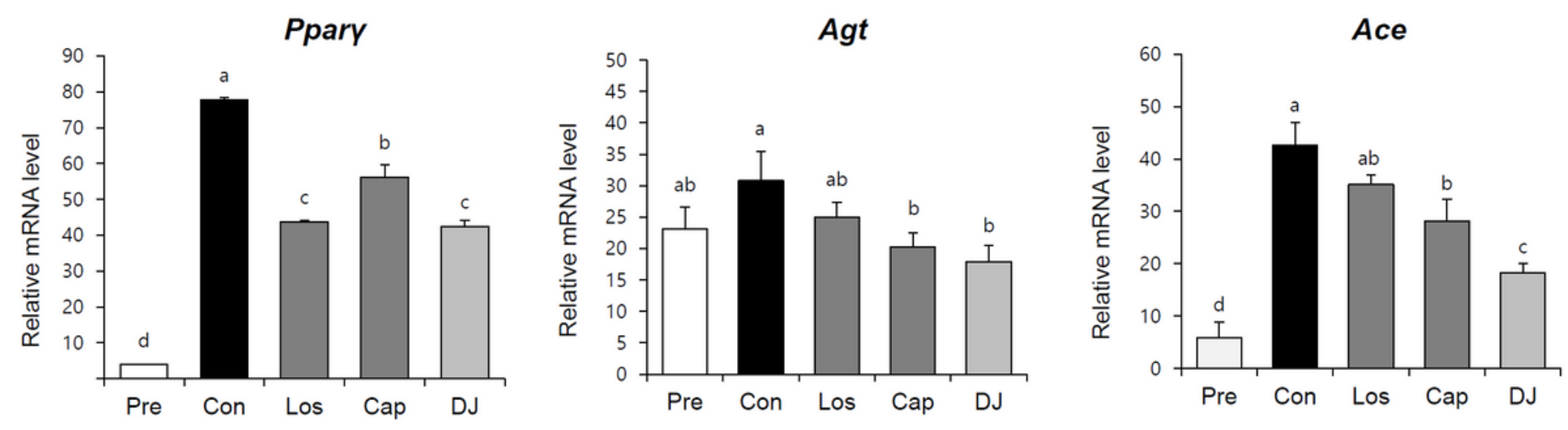

Figure 11

Effects of Doenjang extract on 3T3-L1 cell line. Values with different superscripts are significantly different $(p<0.05)$ by ANOVA with Duncan's multiple range test $(a>b)$. Pre; preadipocytes, Con; adipocytes without 
any treatment, Los; adipocytes treated with losartan (10-4 M), Cap; adipocytes treated with captopril (10-4 M), DJ; adipocytes treated with doenjang ( $0.4 \%$ salinity). Pparg; peroxisome proliferator-activated receptor gamma, Agt, Angiotensinogen, Ace; Angiotensin-converting enzyme. 